\title{
Reduction Expansion Synthesis as Strategy to Control Nitrogen Doping Level and Surface Area in Graphene
}

\author{
Russell Canty ${ }^{1}$, Edwin Gonzalez ${ }^{1}$, Caleb MacDonald ${ }^{1}$, Sebastian Osswald ${ }^{2}$, Hugo Zea ${ }^{3}$ and \\ Claudia C. Luhrs ${ }^{1, *}$
}

Received: 2 September 2015 ; Accepted: 9 October 2015 ; Published: 16 October 2015

Academic Editor: Dusan Losic

1 Mechanical and Aerospace Engineering Department, Naval Postgraduate School, Monterey, CA 93943, USA; cantyrs@illinois.navy.mil (R.C.); edwin7gonzalez@gmail.com (E.G.); caleb.macdonald012@gmail.com (C.M.)

2 School of Materials Engineering, Purdue University, West Lafayette, IN 47907-2045, USA; sosswald@purdue.edu

3 Departamento de Ingeniería Química y Ambiental, Universidad Nacional de Colombia, Bogotá, 111321, Colombia; hrzear@unal.edu.co

* Correspondence: ccluhrs@nps.edu; Tel.: +1-831-656-2568

\begin{abstract}
Graphene sheets doped with nitrogen were produced by the reduction-expansion (RES) method utilizing graphite oxide (GO) and urea as precursor materials. The simultaneous graphene generation and nitrogen insertion reactions are based on the fact that urea decomposes upon heating to release reducing gases. The volatile byproducts perform two primary functions: (i) promoting the reduction of the GO and (ii) providing the nitrogen to be inserted in situ as the graphene structure is created. Samples with diverse urea/GO mass ratios were treated at $800{ }^{\circ} \mathrm{C}$ in inert atmosphere to generate graphene with diverse microstructural characteristics and levels of nitrogen doping. Scanning electron microscopy (SEM) and transmission electron microscopy (TEM) were used to study the microstructural features of the products. The effects of doping on the samples structure and surface area were studied by X-ray diffraction (XRD), Raman Spectroscopy, and Brunauer Emmet Teller (BET). The GO and urea decomposition-reduction process as well as nitrogen-doped graphene stability were studied by thermogravimetric analysis (TGA) coupled with mass spectroscopy (MS) analysis of the evolved gases. Results show that the proposed method offers a high level of control over the amount of nitrogen inserted in the graphene and may be used alternatively to control its surface area. To demonstrate the practical relevance of these findings, as-produced samples were used as electrodes in supercapacitor and battery devices and compared with conventional, thermally exfoliated graphene.
\end{abstract}

Keywords: reduction-expansion-synthesis; nitrogen-doped graphene

\section{Introduction}

It is well known that the methods used to fabricate and process materials largely determine the characteristics of the resulting products and are therefore key to achieve the desired properties and performance. Graphene, the two dimensional material consisting of an atom thick layer of carbon in a sp ${ }^{2}$ hexagonal arrangement [1], and its derivatives, are no exception. In recent years, the number of reports attempting to tailor graphene properties has grown at stunning rates [2]. One of the common routes used to generate graphene uses graphite oxide (GO) as feedstock [3,4]. GO can be easily generated from the oxidative treatment of graphite flakes $[5,6]$. Once the oxygen groups provided by these procedures have been attached to the graphite structure to generate GO, its transformation to graphene can be performed by various reducing methods, including thermal annealing [3], plasma treatment [7], sonication [8,9], electrochemical routes [10] and use of multiple reducing agents [11-15]. 
This manuscript describes the use of GO along with a reducing expansion agent, to produce doped graphene in which the amount of nitrogen, or alternatively the surface area, can be controlled.

While graphene produced from GO has been reported as a material with a promising electrochemical performance when used for the manufacture of supercapacitor and lithium ion battery electrodes, its practical energy storage capacity is still well below the theoretical values $[16,17]$. There are, however, strategies to improve electrochemical properties and specific capacitance/capacity of graphene, including the incorporation of heteroatoms (e.g., N, B and O), which are known to be electron donors capable to modify the electronic structure of graphene [18-21]. Several doping methods were found to successfully incorporate nitrogen atoms into graphene, including chemical vapor deposition [20,22,23], arc discharge, nitrogen plasma [24,25], and thermal treatments $[14,26,27]$. Unfortunately, the majority of these methods suffer from high cost, low yield, and/or use of toxic precursors, or involve sophisticated equipment that makes scalability impractical. Our group recently introduced the reduction expansion synthesis (RES) using urea as an inexpensive, simple, and easily scalable process to generate nitrogen doped graphene in a single step [12,28-30]. The method was previously employed to produce highly divided reduced metals [31-33].

The intial work, published in 2010 [12], was followed by multiple studies from other authors using urea as reducing agent [34-38]. However, to the best of our knowledge, these reports describe the levels of doping being dependant only on temperature or processing time. With the patent describing the method recently issued [39], it became neccessary to further investigate the effects of urea addition on the properties of the resulting graphene. Here, we provide evidence that the amount of urea in the precursor mixture has a profound effect on the structure and composition of the produced graphene, and may be used to control the level of doping or specific surface area of the material. We finally demonstrate the importance of these findings by reporting the performance of the as-produced graphene as both supercapacitor and lithium ion battery electrodes.

\section{Results and Discussion}

The microstructural characteristics of the nitrogen-doped graphene samples were analyzed by scanning electron microscopy (SEM) and transmission electron microscopy (TEM) (Figures 1 and 2) and compared with thermally exfoliated samples (no urea). The dispersion of the reduced graphene specimens in a solvent using sonication, as preparation step for TEM sample analysis, renders disordered sheets that entangle with each other (Figure 1). Higher magnification images reveal to be $1-5$ atomic layer sheets. The SEM micrographs showed that more than producing a set of individual layers with different orientations, the structure remains attached in certain sections, creating a multilayered architecture similar to a honeycomb. The SEM images of samples with diverse levels of doping (Figure 2) indicate a more compact structure for specimens produced with higher amounts of urea such as mass ratio urea/GO $=0.8$ or 1 .
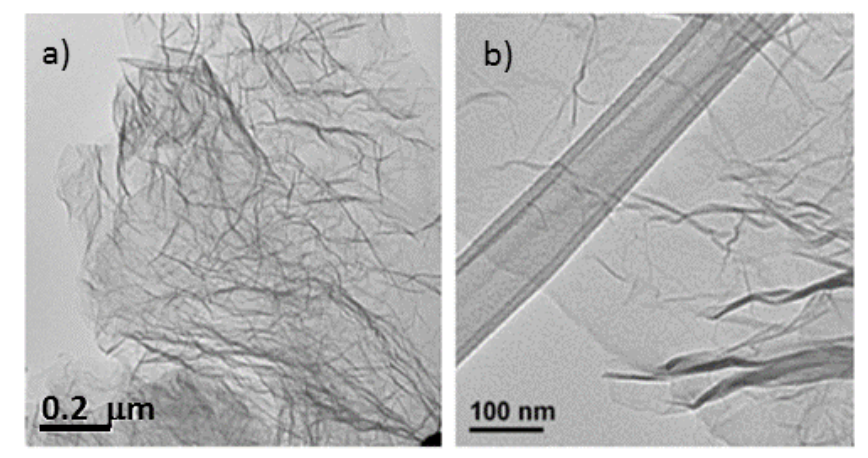

Figure 1. Transmission electron microscopy (TEM) image of the same un-doped sample. (a) Exhibiting entangled graphene sheets; (b) TEM of doped graphene sheet (precursor had a mass ratio urea/graphite oxide (GO) of 0.25 ) displaying a wrinkled sheet. 

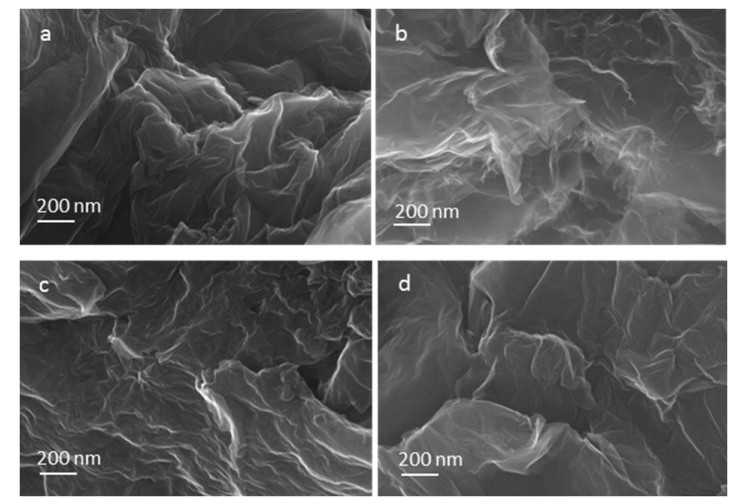

Figure 2. Scanning electron microscopy (SEM) images of samples with diverse doping levels. (a) Thermally exfoliated Graphene; (b) Graphene produced from precursor with mass ratio urea/GO = 0.6; (c) mass ratio urea $/ \mathrm{GO}=0.8$ and $(\mathbf{d})$ mass ratio urea $/ \mathrm{GO}=1$.

The first evidence of nitrogen insertion in the doped samples was encountered in the spectroscopic data generated. The energy dispersive X-ray spectroscopy (EDS) spectra (Supplementary Materials Figure S1) of samples prepared with urea present a clear nitrogen peak located between the carbon and oxygen peaks, near $0.4 \mathrm{keV}$, while the specimen reduced by simple thermal exfoliation lacked such a feature. Previous studies commented on the amounts of oxygen encountered in thermally reduced samples; the GO loses most of the oxygen functional groups but the conversion does not reach a $100 \%$. Some studies $[7,12]$ estimate that thermal exfoliation routes alone render $10 \%-11 \%$ oxygen in the reduced graphene final structure, making the appearance of a small oxygen peak in the EDS spectra, as the ones observed in this study, an expected outcome. When the samples were analyzed by energy electron loss spectroscopy (EELS), the presence of nitrogen was confirmed by the appearance of additional peaks above $400 \mathrm{eV}$, along the characteristic graphitic $1 \mathrm{~s}-\pi^{*}$ and $1 \mathrm{~s}-\sigma^{*}$ peaks in the K-edge region at 285 and $291 \mathrm{eV}$, respectively reported by other studies [40,41].

To obtain further insight into potential structural changes in the graphene with increasing urea content, we analyzed all samples using X-ray diffraction (XRD). The obtained XRD patterns (Figure 3a) reveal a shift in the $d_{002}$ peak toward higher angles (smaller interlayer spacing) as the urea/GO ratio in the precursor increases. This suggest that the presence of urea not only affects the exfoliation process, but that the amount of urea may be used to control the level of exfoliation and thus the interlayer spacing in graphene samples. As shown previously, the decomposition of urea generates additional volatile species that aid the reduction of the GO (more complete reduction), but also results in an overall less effective expansion process [28]. Consequently, with increasing urea/GO mass ratio, the level of exfoliation decreases and the interlayer spacing is approaching that of graphite. This effect has been observed before in other nitrogen doped graphene samples; prior work has hypothesized that a reduction in the interlayer spacing, as nitrogen is introduced into the graphene structure, might be due to ammonia corrosive processes [42] or to the sheet defective structure [43]. However, given the different nitrogen species encountered when doping graphene (in graphitic, pyridinic, and pyrrolic configurations) it is also conceivable that an uneven distribution of charges in the different sheets promote the creation of attractive forces that increase their interactions. This phenomenon is worth further investigation and will be the subject of attention in future research. In addition, it can be noted that the relative intensity of the (100)/(101) features also increases with increasing urea content, resulting in a more complete reduction and a smaller number of in-plane defects. At the same time, other byproducts of the urea decomposition (e.g., ammonia) react with the graphene, leading to the incorporation of nitrogen atoms into the carbon lattice (doping), as discussed in detail in a previous studies [12,34,36,37].

Figure $3 \mathrm{~b}$ depicts the first and second order Raman spectra of the urea/GO-derived graphene samples, in comparison to thermally exfoliated graphene. All spectra exhibit the characteristic defect-induced $\mathrm{D}$ band and graphitic $\mathrm{G}$ band of $\mathrm{sp}^{2}$-carbons, as well as the resulting second order and combination modes. 
The most notable spectral change is the increase in the D band-to-G band intensity ratio $\left(I_{\mathrm{D}} / \mathrm{I}_{\mathrm{G}}\right)$ with increasing urea content. Although, according to XRD data (Figure 4), both in-plane and stacking order increase with higher urea content, the number of nitrogen atoms incorporated into the carbon lattice also rises. The nitrogen atoms are defects within the graphene lattice (substitutable impurities), and consequently, contribute to the $\mathrm{D}$ band intensity, yielding the observed increase in $I_{\mathrm{D}} / I_{\mathrm{G}}$. The $I_{\mathrm{D}} / I_{\mathrm{G}}$ value of the thermally exfoliated sample is higher $(\sim 1.06)$ than most urea/GO-derived samples, even without any nitrogen inclusions. This discrepancy results from differences in the exfoliation mechanism as previously discussed [28]. Given this sensitivity to the presence of nitrogen impurities, the $I_{\mathrm{D}} / I_{\mathrm{G}}$ therefore provides a fast and convenient tool to estimate the concentration of nitrogen atoms in doped-graphene samples. For a more detailed description of the Raman spectra of urea/GO-derived graphene samples, the reader is referred to work by Mowry et al. [28].

a)

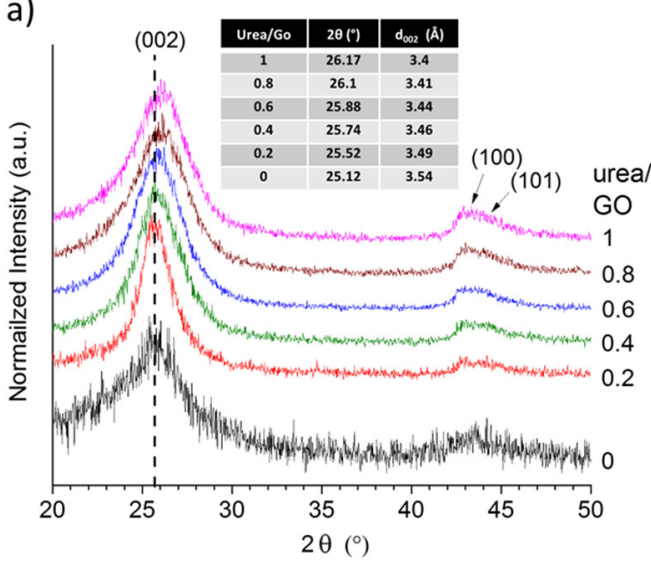

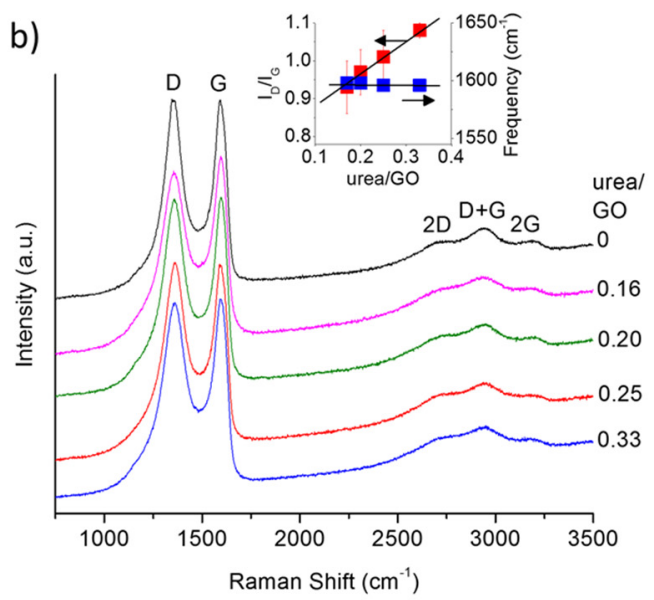

Figure 3. X-ray diffraction (XRD) pattern showing a shift in the $d_{002}$ peak toward higher angles as the urea/GO ratio in the precursor increases (a) and Raman spectra (b) of urea/GO-derived samples in comparison to thermally exfoliated graphene. The Raman intensity ratio between $\mathrm{D}$ and $\mathrm{G}$ band, $I_{\mathrm{D}} / \mathrm{I}_{\mathrm{G}}$, increases with increasing urea content while the $\mathrm{G}$ band position remains nearly unchanged (right insert).

While Raman measurements provided indirect evidence for a direct relationship between urea content and level of $\mathrm{N}$-doping, we conducted thermogravimetric analysis (TGA) coupled with mass spectroscopy (MS) to directly evaluate the $\mathrm{N}$-content of the samples. TGA was also conducted in order to identify the differences in thermal stability of the diverse samples. The burn off temperatures of the specimens were studied under an oxygen-containing atmosphere and the mass spectral signal of the byproducts generated as the carbon structure burns off. Figure 4a presents the first derivative of the mass as a function of the temperature. The minima indicate the temperatures at which the highest mass loss occurred. Such temperature value for each peak is listed in the inset table for the figure and further demonstrates the dramatic shift in thermal stability. The burn off process for the sample with no nitrogen, thermally reduced graphene (no urea in precursor), yielded a mass loss peak temperature of $611.9^{\circ} \mathrm{C}$. The addition of nitrogen to the graphene structure shifts the position of the mass loss derivative, such that, for a sample prepared from a urea/GO 1/1 ratio the peak position is $677.1{ }^{\circ} \mathrm{C}$, providing evidence that the thermal stability increases for the doped material. It is important to note that the oxidation of all samples starts in a similar temperature range around $475-520^{\circ} \mathrm{C}$. However, the rate of oxidation (slope of curve) at the early stages of the burn-off and the total temperature window in which the oxidation takes place (width of the curve) vary substantially.

The TGA-MS results are thus in good agreement with XRD and Raman data, providing further evidence for the increment in structural order with increasing urea content. While all samples consist of graphitic $\mathrm{sp}^{2}$ (hence similar onset temperatures for oxidation), the burn off rate is higher for samples containing less urea. These samples are more exfoliated, and thus more porous, as compared 
to graphene with higher stacking order. At temperatures around $500{ }^{\circ} \mathrm{C}$, mass transport becomes the rate-limiting reaction step in carbon nanomaterial oxidation, leading to reduced oxidation rate in low porosity materials. In addition, the lower concentration of two dimensional defects (due to nitrogen repair of lattice defects during exfoliation with urea in a nitrogen atmosphere) also contributes to the higher thermal stability with increasing urea content.

Mass spectra analyses of gasses generated during TGA runs revealed the formation of $\mathrm{CO}_{2}$ as main byproduct for pure graphene and $\mathrm{CO}_{2}$ and $\mathrm{NO}$ for doped graphene under the atmosphere and conditions used. As concentrations of nitrogen in the precursor increase, the temperature at which maximum $\mathrm{NO}$ and $\mathrm{CO}_{2}$ leave the structure/off gas increases (Figure 4a). The mass spectroscopy data recorded during burn-off for $\mathrm{NO}$ (mass 30 ), that is, the measured ion current normalized to the sample weight to account for differences in sample mass, follow an upward trend as the amount of urea in the samples increase. With the exception of one of the points, the rest of values confirmed the larger amounts of nitrogen in the samples as the urea/GO mass ratio increase.
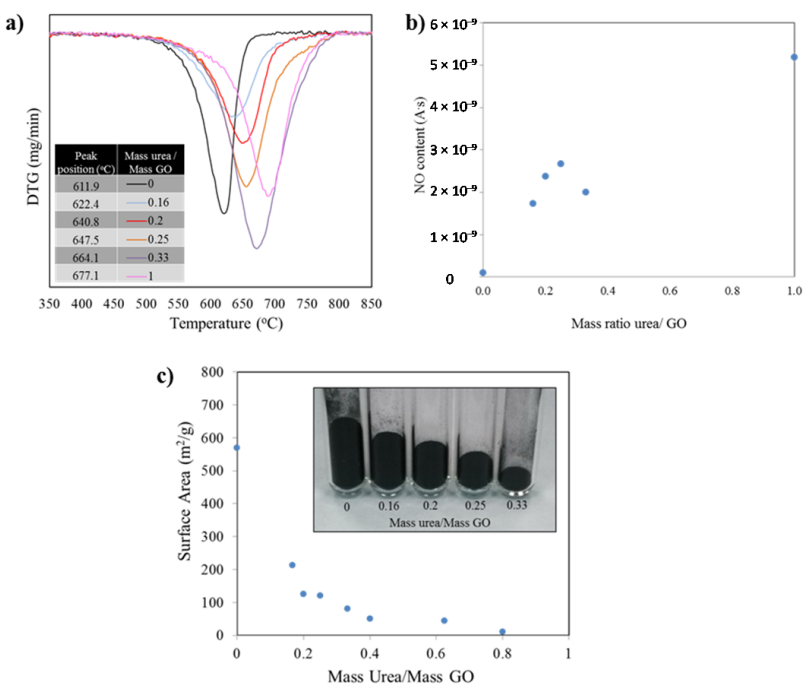

Figure 4. (a) Derivative (DTG) curve of the weight loss observed during the samples burn off process shifts to higher temperatures as the amounts of nitrogen introduced in the structures increase; (b) Corresponding mass spectroscopy data recorded during burn-off (mass 30). The measured ion current was normalized to the sample weight to account for differences in sample mass; (c) Variation in surface area values as the mass ratio of urea/GO increase. The same mass of sample for diverse formulations show a significant difference in mass volume.

The Brunauer Emmet Teller (BET) surface area measurements for samples with diverse doping levels show an exponential decay as the amount of urea used in the precursor increase (correlated to the nitrogen doping level). Such change is also evident when weighing the same amount of the different powders: As the amount on nitrogen introduced increase, the level of exfoliation decreases. See Figure 4c inset. After a value of mass ratio urea / GO of 0.6 is reached, the surface area collapses to values near to that of untreated graphite. It is worth noting that by modifying the amount of urea in the precursor mix, the surface area value in the resulting product can be controlled. Measurements were conducted multiple times to corroborate repeatability, in all cases falling within a $5 \%$ of the expected values.

For the supercapacitor tests, the specific capacitance of some of the samples are plotted in Figure 5a, revealing a maximum value for thermally exfoliated graphene (no urea) when measured in F/g. This result can be related to the high surface area of the material yielding a similarly high specific capacitance. After 50 cycles the capacitance for the pure graphene, that started at a value of $400 \mathrm{~F} / \mathrm{g}$, approached $127 \mathrm{~F} / \mathrm{g}$. The latter value is consistent with results $(117 \mathrm{~F} / \mathrm{g})$ obtained by other groups [4,39-42]. The large reduction in surface area between un-doped and doped graphene dominates the capacitance, as the lowest doping concentration resulted in a threefold decrease in 
surface area and a similar reduction in capacitance. The reduction in capacitance ranged from a $70 \%$ decrease to $90 \%$ in specific capacitance for ratios 0.25 and 0.16 , respectively. When the data is transformed to normalize surface area values, using $\mathrm{F} / \mathrm{m}^{2}$ (Figure $5 \mathrm{~b}$ ) instead of $\mathrm{F} / \mathrm{g}$ units (Figure $5 \mathrm{a}$ ), an optimal doping for the sample generated from mass ratio urea/GO precursor of 0.25 is identified. The later shows a $50 \%$ more specific capacitance than sample 0.33 and $300 \%$ more specific capacitance than sample with ratio of 0.2. That is, for similar values of surface area, the doped sample which precursor was made from urea/GO ratios of 0.25 outperforms the thermally exfoliated graphene sample (no urea added).

The sample identified as 0.25 (mass ratio urea/GO precursor) demonstrated superior capacitive characteristics to the un-doped graphene proving that the doping has a positive benefit to the electrical properties of the material. The 0.33 sample performed nearly identically to the bare thermally exfoliated graphene. The 0.2 and 0.16 samples demonstrated worse electrical characteristics than others, further emphasizing the presence of an optimal peak doping concentration in the vicinity of 0.25 .

Nitrogen-doped graphene has also been reported to provide superior electrochemical performance and cycle stability in Li-ion batteries, as compared to pristine graphene $[44,45]$. The enhanced Li uptake has been ascribed to a larger number of defects and increased disorder as well as the higher electronegativity of $\mathrm{N}$-doped graphene.

Figure 6 compares the first lithiation/delithiation cycle of an urea/GO-derived (mass ratio $=1$ ) sample with that of thermally exfoliated graphene, using a C-rate of $C / 10$ (with $1 \mathrm{C}=372 \mathrm{~mA} / \mathrm{g}$ ).

As expected, the thermally exfoliated graphene is subject to a high irreversible capacity loss (>1600 mAh/g), exhibiting a reversible specific capacity of $\sim 860 \mathrm{mAh} / \mathrm{g}$ at the end of the 1 st cycle. However, in contrast to previous studies [44,45], the N-doped graphene showed lower irreversible and reversible capacities of 315 and $470 \mathrm{mAh} / \mathrm{g}$, respectively. This is an important finding for several reasons. (1) Unlike in early studies, N-doping via thermal exfoliation of urea-/GO mixtures yields samples with higher structural order and less specific surface area. Therefore, the effects of nitrogen defects and structural disorder on overall Li uptake can be decoupled; (2) Surface area and nitrogen content can be controlled by adjusting the urea/GO mass ratio. This is important, as from a practical point of view, high reversible capacities are not necessarily favorable if they are linked to very high irreversible 1st cycle capacities, which raises challenges in cell manufacturing and anode/cathode balancing. More favorable are materials that exceed the practical specific capacity of graphite $(\sim 330 \mathrm{mAh} / \mathrm{g})$, but also maximize the $\mathrm{C}_{\text {reversible }} / \mathrm{C}_{\text {irreversible }}$ capacity ratio. Under this consideration, $\mathrm{N}$-doped graphene would be the more favorable anode material (0.52 vs. 1.49); (3) Given the lower surface area values of $\mathrm{N}$-doped graphene $\left(<10 \mathrm{~m}^{2} / \mathrm{g}\right)$, we can conclude that the addition of urea is an effective way to control the extent of GO exfoliation, allowing for the

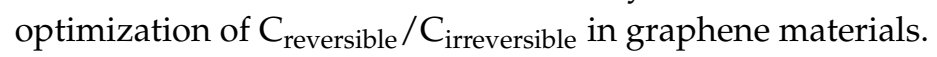
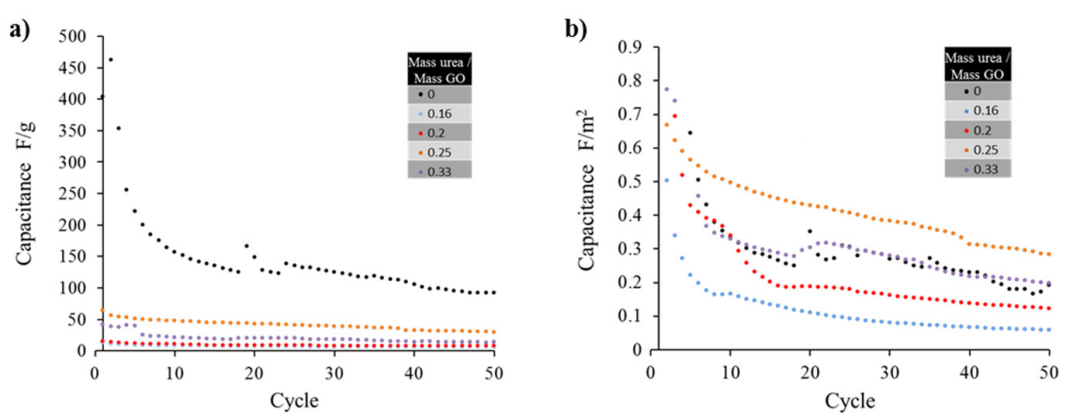

Figure 5. (a) The capacitance values of the samples drastically decrease after the first 10 cycles, only the sample with un-doped graphene (mass ratio urea/GO $=0$ ) seems to maintain high capacitance (ca. above $100 \mathrm{~F} / \mathrm{g}$ ); (b) Capacitance values normalized as $\mathrm{F} / \mathrm{m}^{2}$ show that the nitrogen doping actually improves the cycle life when samples surface area is considered, reaching a maximum for the sample prepared with an urea/GO mass ratio of 0.25 . 
The resulting capacitance of the un-doped graphene prepared by thermal exfoliation in units of F/g was remarkably higher when compared with doped samples. Specific capacitance has been strongly correlated to the surface area of the graphene or doped graphene employed in the electrode material. Such phenomenon could be explained when relating the capacitance to the number of charges interacting at the electric double layer: the higher the surface area, the larger the sites where charges in the interface could be created. However, once the capacitance values get normalized by surface area, using $\mathrm{F} / \mathrm{m}^{2}$ units, there seems to be an optimal value (sample with 0.25 ), demonstrating that despite the reduction in surface area, there must be an addition in charge mobility that improves sample performance.

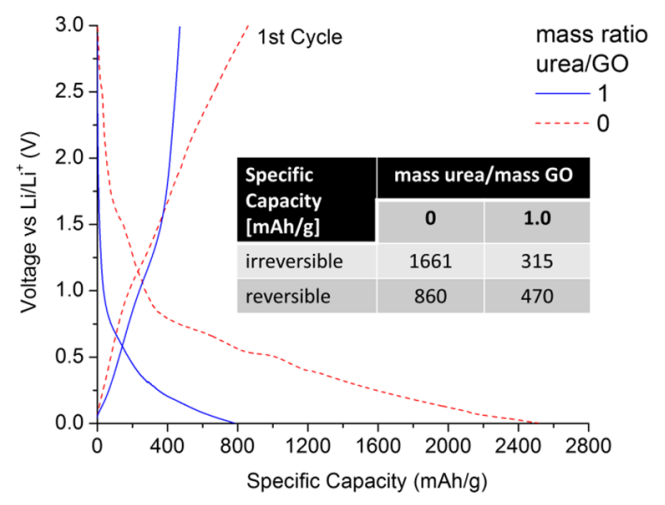

Figure 6. Lithiation/delithiation voltage profiles of urea/GO-derived graphene (mass ratio of 1.0) in comparison to thermally exfoliated graphene. All data were recorded in half-cell configuration (vs. $\mathrm{Li} / \mathrm{Li}^{+}$) using a current of $\mathrm{C} / 10$.

Electrochemical testing demonstrated that addition of urea offers a unique pathway to optimize the critical $C_{\text {reversible }} / C_{\text {irreversible }}$ ratio in lithium ion batteries. High control over surface area and interlayer spacing may also provide opportunities for other advanced battery technologies, such as sodium ion batteries, where conventional graphitic materials are unsuitable.

While an in-depth discussion of the electrochemical performance of urea/GO-derived graphene is outside the scope of this study and will be published elsewhere, the presented data demonstrates the unique characteristics of urea/GO-derived graphene and the opportunities in energy storage applications.

\section{Experimental Section}

\subsection{Materials and Methods}

GO was produced from synthetic graphite powder (particle size $<20 \mu \mathrm{m}$, Aldrich, St. Louis, MO, USA) following a variation of the Hummer's method [46]. A mixture of $20 \mathrm{~mL}$ of phosphoric and $180 \mathrm{~mL}$ of sulfuric acid (ACS reagent, Aldrich) was added to $1.5 \mathrm{~g}$ of graphite powder. Once a complete dispersion of the powder was obtained, $9 \mathrm{~g}$ of potassium permanganate (J.T. Baker, Mumbai, India) were mixed into the suspension. The mixture was kept under constant stirring for $330 \mathrm{~min}$ followed by the slow addition of $150 \mathrm{~g}$ of ice (de-ionized). The suspension was kept at $35{ }^{\circ} \mathrm{C}$ while $1.9 \mathrm{~mL}$ of $30 \%$ hydrogen peroxide were added. The supernatant and precipitate were separated by centrifugation. The precipitate, oxidized graphite (GO), was subject to three rinsing steps to remove undesired byproducts; the first one was conducted utilizing $30 \% \mathrm{HCl}$, the second with de-ionized water, and ethanol was used for the final step. The GO powder was then dried.

Doped graphene was produced in situ via the thermal reduction of graphite oxide in the presence of urea under inert atmosphere (reduction expansion synthesis). A sample in which no urea was employed, along mixtures with urea/GO ratios of $0.16,0.2,0.25,0.33,0.4,0.6,0.8$, and 1 were used as 
precursors. The urea/GO mixtures were ground by hand in a mortar, placed in an alumina boat, and introduced into a quartz tube provided with airtight end adapters for atmosphere control. The quartz tube was flushed with nitrogen and inserted for $10 \mathrm{~min}$ into a Lindberg tubular furnace preheated to $800{ }^{\circ} \mathrm{C}$. Previous studies demonstrated that the urea completely decomposes by $600{ }^{\circ} \mathrm{C}$, however, by heating to $800{ }^{\circ} \mathrm{C}$ the mixtures seem to achieve a greater degree of expansion and oxygen groups loss, producing a higher quality product [28]. The resulting powders were characterized by multiple techniques as described below.

\subsection{Sample Characterization}

Scanning and transmission electron microscopy were employed to study the microstructure of the samples. A Zeiss Neon 40 (Carl Zeiss Inc., Thornwood, NY, USA) operating between 2-20 kV was employed for SEM studies. A JEOL 2010F FASTEM (JEOL Peabody, MA, USA) field emission gun STEM/TEM equipped with Gatan image filtering (GIF) (Gatan Inc., Warrendale, PA, USA) system was used to acquire the TEM and EELS data. Energy dispersive X-ray spectroscopy was performed utilizing the TEM.

Powder samples were analyzed by X-ray diffraction using a Philips PW1830 X-ray diffractometer (Philips, Eindhoven, The Netherlands) operating in a continuous scan mode from a $2 \theta$ of $5^{\circ}$ to $70^{\circ}$. Two second steps were utilized with a step size of $0.020^{\circ}$ at a speed of $0.01^{\circ} \mathrm{s}^{-1}$. The $\mathrm{Cu} \mathrm{X}$ rays generated had a $\lambda$ of $1.5418 \AA$. The diffraction data was analyzed using Xpert Highscore Software (PANalytical, Westborough, MA, USA) using the ICDD PDF2 (International Center for Diffraction Data, Powder Diffraction Files version 2) database.

Raman spectroscopy studies were carried out using an inVia confocal raman microspectrometer (Renishaw Corp., Gloucestershire, UK) with 514-nm laser excitation under ambient conditions. Spectra were recorded using a total accumulation time of $20 \mathrm{~s}$.

Nitrogen isotherms were used to determine total surface area and micropore volume distribution employing Brunauer Emmet Teller (BET) and Horvath-Kawazoe (HK) methodologies, respectively. A Quantachrome Nova 4200e surface area and pore size analyzer (Quantachrome, Boynton Beach, FL, USA) using $9 \mathrm{~mm}$ large bulb long cell was employed for this analysis. Samples were degassed following an increasing temperature profile, starting at $100^{\circ} \mathrm{C}$ for $30 \mathrm{~min}$, followed by $300^{\circ} \mathrm{C}$ for $150 \mathrm{~min}$.

Thermogravimetric and evolved gas mass spectral analyses were performed to identify the various off gassing temperatures and constituents of heated samples. A Netzsch STA 449 F3 Jupiter connected to a MS403C Aëolos mass spectrometer (Netzsch GmbH \& Co. KG Selb, Germany) was used. The temperature programmed oxidation of the doped samples generated in the furnace was conducted in an atmosphere that contained $80 \%$ inert gas and $20 \%$ oxygen (simulated air) with the intent of promoting the burn off of both the un-doped graphene and the doped samples.

\subsection{Electrochemical Testing}

Capacitor and battery electrodes were fabricated using a mixture of the as-produced graphene or doped graphene, acetylene black, N-Methyl-2-pyrrolidone (NMP) and polyvinylidene fluoride (PVDF) (MIT Corp., Richmond, CA, USA). For supercapacitor testing, the resultant slurry was spread onto $25 \mu \mathrm{m}$ thick roughened nickel foil to a height of $350 \mu \mathrm{m}$ using a film applicator, placed into a Barnstead Lab-Line L-C oven (Thermo Scientific, Waltham, MA, USA) at $100{ }^{\circ} \mathrm{C}$ for $1 \mathrm{~h}$ and then punched into $15 \mathrm{~mm}$ disks using a MTI Corporation precision disc cutter. The completed electrodes were assembled in pairs between two acrylic non-conductive polymeric blocks, separated by a celgrad membrane (Celgrad, Charlotte, NC, USA) soaked in electrolyte $\mathrm{KOH}$ solution. For battery electrode preparation, slurries were cast on a copper foil using a blade-applicator. The dried electrodes (thickness $\sim 0.2 \mathrm{~mm}$ ) were cut to $12 \mathrm{~mm}$-diameter disks, transferred to an Ar-filled glovebox, and assembled in CR2032 coin cells in half-cell configuration (lithium metal anode). Electrochemical testing was conducted in an electrolyte containing $1 \mathrm{M} \mathrm{LiPF}_{6}$ in EC:DMC:DEC (1:1:1). 
Battery and capacitor testing was conducted using a Maccor Model 4200M tester (Maccor, Tulsa, OK, USA). Capacitance was evaluated by applying three different current sources for a set number of cycles and measuring the resultant voltage trends. The currents and number of cycles utilized were 150,350 , and $500 \mu \mathrm{A}$ for 50,50 , and 20 cycles, respectively. Battery testing was conducted using a charge/discharge rate current of $\mathrm{C} / 10$.

\section{Conclusions}

We were able to successfully dope graphene with nitrogen functional groups with a high level of control over the degree of doping utilizing the reduction expansion synthesis (RES) method.

SEM and TEM analysis revealed that the graphene produced resulted in thin sheets of disordered graphene, as is typical for samples made by reduction of graphite oxide. EELS analysis provided unequivocal evidence that nitrogen was embedded in the structure of graphene. Similarly, EDS shows nitrogen peaks in the doped samples further demonstrating the effectiveness of RES in doping the graphene. The BET surface area measurements for samples with diverse doping levels show an exponential decay as the amount of urea used in the precursor increase. These values can be controlled by modifying the amount of urea in the precursor samples.

XRD analysis of various levels of doped graphene revealed peak shifts indicating lower interplanar spacing " $d$ " of the (002) planes as the concentration of nitrogen increased. The Raman intensity ratio between $\mathrm{D}$ and $\mathrm{G}$ band, $I_{\mathrm{D}} / \mathrm{I}_{\mathrm{G}}$, increases with increasing urea content while the $\mathrm{G}$ band position remains nearly unchanged. These results confirmed the trends observed by BET analysis and indicated that there is a pronounced surface area loss as the amount of doping increases.

All doped samples demonstrated to have high thermal stability up to $550{ }^{\circ} \mathrm{C}$ when studied by TGA and mass spectral analysis performed under temperature programmed oxidation conditions. The MS data corroborated that the amount of urea in the precursor samples can be directly linked to the amount of nitrogen species lost during temperature programmed oxidation/burn off of the samples, thus providing a path to control the amount of nitrogen species included in the structure and the surface area of the products.

Indeed, the introduction of nitrogen impurities by RES method in graphene produced from GO had a large effect in the graphene structure and improved the performance of electrodes based on such nitrogen doped graphene. Doping graphene with nitrogen clearly represents a step ahead in the development of electrode materials for new energy storage devices and the method presented herein provides a route to introduce a controlled amount of nitrogen and imprint a specific surface area in the products.

Supplementary Materials: The following are available online at www.mdpi.com/1996-1944/8/10/5359/s1.

Acknowledgments: This work was supported by the Marine Corps Expeditionary Energy Office.

Author Contributions: C.C.L. conceived and designed the experiments; H.Z., R.C. and E.G. performed the synthesis and sample microstructural characterization; R.C., H.Z. and C.C.L. analyzed the thermal behavior of products; C.C.L., S.O. and H.Z. analyzed the data; S.O. and C.C.L. performed the supercapacitor evaluation, S.O. and C.M. conducted the battery tests; C.C.L. and S.O. wrote the paper.

Conflicts of Interest: The authors declare no conflict of interest.

\section{References}

1. Meyer, J.C.; Geim, A.K.; Katsnelson, M.I.; Novoselov, K.S.; Booth, T.J.; Roth, S. The structure of suspended graphene sheets. Nature 2007, 446, 60-63. [CrossRef] [PubMed]

2. Barth, A.; Marx, W. Graphene-A Rising Star in View of Scientometrics. 2008. Available online: http://www.researchgate.net/profile/Andreas_Barth/publication/1771596_Graphene_-_A_rising_star_ in_view_of_scientometrics/links/0912f50fd540ea7413000000.pdf (accessed on 13 October 2015).

3. McAllister, M.J.; Li, J.; Adamson, D.H.; Schniepp, H.C.; Abdala, A.A.; Liu, J.; Herrera-Alonso, M.; Milius, D.L.; Car, R.; Prud'homme, R.K.; et al. Single sheet functionalized graphene by oxidation and thermal expansion of graphite. Chem. Mater. 2007, 19, 4396-4404. [CrossRef] 
4. Rao, C.N.R.; Sood, A.K.; Subrahmanyam, K.S.; Govindaraj, A. Graphene: The new two-dimensional nanomaterial. Angew. Chem. Int. Ed. 2009, 48, 7752-7777. [CrossRef] [PubMed]

5. Hummers, W.; Offeman, R. Preparation of graphitic oxide. J. Am. Chem. Soc. 1958, 80, 1339. [CrossRef]

6. Brodie, B.C. On the atomic weight of graphite. Phil. Trans. R. Soc. Lond. 1859, 149, 249-259. [CrossRef]

7. Lambert, T.N.; Luhrs, C.C.; Chavez, C.A.; Wakeland, S.; Brumbach, M.T.; Alam, T.M. Graphite oxide as a precursor for the synthesis of disordered graphenes using the aerosol-through-plasma method. Carbon 2010, 48, 4081-4089. [CrossRef]

8. Cravotto, G.; Cintas, P. Sonication-assisted fabrication and post-synthetic modifications of graphene-like materials. Chem. Eur. J. 2010, 16, 5246-5259. [CrossRef] [PubMed]

9. Choucair, M.; Thordarson, P.; Stride, J.A. Gram-scale production of graphene based on solvothermal synthesis and sonication. Nat. Nanotechnol. 2009, 4, 30-33. [CrossRef] [PubMed]

10. Liu, X.; Qi, X.; Zhang, Z.; Ren, L.; Hao, G.; Liu, Y.; Wang, Y.; Huang, K.; Wei, X.; Li, J.; Huang, Z.; Zhong, J. Electrochemically reduced graphene oxide with porous structure as a binder-free electrode for high-rate supercapacitors. RSC Adv. 2014, 4, 13673-13679. [CrossRef]

11. Pham, V.H.; Hur, S.H.; Kim, E.J.; Kim, B.S.; Chung, J.S. Highly efficient reduction of graphene oxide using ammonia borane. Chem. Commun. 2013, 49, 6665-6667. [CrossRef] [PubMed]

12. Wakeland, S.; Martinez, R.; Grey, J.K.; Luhrs, C.C. Production of graphene from graphite oxide using urea as expansion-reduction agent. Carbon 2010, 48, 3463-3470. [CrossRef]

13. Stankovich, S.; Dikin, D.A.; Piner, R.D.; Kohlhaas, K.A.; Kleinhammes, A.; Jia, Y.; Wu, Y.; Nguyen, S.T.; Ruoff, R.S. Synthesis of graphene-based nanosheets via chemical reduction of exfoliated graphite oxide. Carbon 2007, 45, 1558-1565. [CrossRef]

14. Li, X.; Wang, H.; Robinson, J.T.; Sanchez, H.; Diankov, G.; Dai, H. Simultaneous nitrogen doping and reduction of graphene oxide. J. Am. Chem. Soc. 2009, 131, 15939-15944. [CrossRef] [PubMed]

15. Nethravathi, C.; Rajamathi, M. Chemically modified graphene sheets produced by the solvothermal reduction of colloidal dispersions of graphite oxide. Carbon 2008, 46, 1994-1998. [CrossRef]

16. Ji, L.; Lin, Z.; Alcoutlabi, M.; Zhang, X. Recent developments in nanostructured anode materials for rechargeable lithium-ion batteries. Energy Environ. Sci. 2011, 4, 2682-2699. [CrossRef]

17. Wu, Z.; Ren, W.; Xu, L.; Li, F.; Cheng, H. Doped graphene sheets as anode materials with superhigh rate and large capacity for lithium ion batteries. Acs Nano 2011, 5, 5463-5471. [CrossRef] [PubMed]

18. Paek, E.; Pak, A.J.; Kweon, K.E.; Hwang, G.S. On the origin of the enhanced supercapacitor performance of nitrogen-doped graphene. J. Phys. Chem. C 2013, 117, 5610-5616. [CrossRef]

19. Han, J.; Zhang, L.L.; Lee, S.; Oh, J.; Lee, K.; Potts, J.R.; Ji, J.; Zhao, X.; Ruoff, R.S.; Park, S. Generation of B-doped graphene nanoplatelets using a solution process and their supercapacitor applications. Acs Nano 2013, 7, 19-26. [CrossRef] [PubMed]

20. Luo, Z.; Lim, S.; Tian, Z.; Shang, J.; Lai, L.; MacDonald, B.; Fu, C.; Shen, Z.; Yu, T.; Lin, J. Pyridinic N doped graphene: Synthesis, electronic structure, and electrocatalytic property. J. Mater. Chem. 2011, 21, 8038-8044. [CrossRef]

21. Wang, D.; Min, Y.; Yu, Y.; Peng, B. A general approach for fabrication of nitrogen-doped graphene sheets and its application in supercapacitors. J. Colloid Interface Sci. 2014, 417, 270-277. [CrossRef] [PubMed]

22. Jin, Z.; Yao, J.; Kittrell, C.; Tour, J.M. Large-scale growth and characterizations of nitrogen-doped monolayer graphene sheets. Acs Nano 2011, 5, 4112-4117. [CrossRef] [PubMed]

23. Qu, L.; Liu, Y.; Baek, J.; Dai, L. Nitrogen-doped graphene as efficient metal-free electrocatalyst for oxygen reduction in fuel cells. Acs Nano 2010, 4, 1321-1326. [CrossRef] [PubMed]

24. Panchakarla, L.S.; Subrahmanyam, K.S.; Saha, S.K.; Govindaraj, A.; Krishnamurthy, H.R.; Waghmare, U.V.; Rao, C.N.R. Synthesis, structure, and properties of boron- and nitrogen-doped graphene. Adv. Mater. 2009, 21, 4726-4730. [CrossRef]

25. Wang, Y.; Shao, Y.; Matson, D.W.; Li, J.; Lin, Y. Nitrogen-doped graphene and its application in electrochemical biosensing. ACS Nano 2010, 4, 1790-1798. [CrossRef] [PubMed]

26. Guo, B.; Liu, Q.; Chen, E.; Zhu, H.; Fang, L.; Gong, J.R. Controllable N-doping of graphene. Nano Lett. 2010, 10, 4975-4980. [CrossRef] [PubMed]

27. Sheng, Z.; Shao, L.; Chen, J.; Bao, W.; Wang, F.; Xia, X. Catalyst-free synthesis of nitrogen-doped graphene via thermal annealing graphite oxide with melamine and its excellent electrocatalysis. ACS Nano 2011, 5, 4350-4358. [CrossRef] [PubMed] 
28. Mowry, M.; Palaniuk, D.; Luhrs, C.C.; Osswald, S. In situ Raman spectroscopy and thermal analysis of the formation of nitrogen-doped graphene from urea and graphite oxide. RSC Adv. 2013, 3, 21763-21775. [CrossRef]

29. Canty, R. Nitrogen doped graphene and its use as electrode in supercapacitor devices. J. Nanosci. Nanotechnol. 2014, 14, 1134-1144.

30. Palaniuk, D.R. Synthesis and characterization of nitrogen-doped graphene. J. Mater. Chem. A 2012, 1, 2248-2255.

31. Zea, H.; Luhrs, C.C.; Phillips, J. Reductive/expansion synthesis of zero valent submicron and nanometal particles. J. Mater. Res. 2011, 26, 672-681. [CrossRef]

32. Soliman, H.; Phillips, J.; Luhrs, C.; Zea, H.; Leseman, Z.C. Aerosol synthesis of nano and micro-scale zero valent nickel particles from oxide precursors. In Proceedings of the ASME 2010 International Mechanical Engineering Congress and Exposition, Vancouver, BC, Canada, 12-18 November 2010.

33. Luhrs, C.; Kane, M.; Leseman, Z.; Phillips, J. Novel process for solid state reduction of metal oxides and hydroxides. Metall. Mater. Trans. B 2013, 44, 115-122. [CrossRef]

34. Li, X.; Yu, X.; Liu, J.; Fan, X.; Zhang, K.; Cai, H.; Pan, N.; Wang, X. Synthesis of nitrogen-doped graphene via thermal annealing graphene with urea. Chin. J. Chem. Phys. 2012, 25, 325-329. [CrossRef]

35. Wu, T.; Shen, H.; Sun, L.; Cheng, B.; Liu, B.; Shen, J. Nitrogen and boron doped monolayer graphene by chemical vapor deposition using polystyrene, urea and boric acid. New J. Chem. 2012, 36, 1385-1391. [CrossRef]

36. Sun, L.; Wang, L.; Tian, C.; Tan, T.; Xie, Y.; Shi, K.; Li, M.; Fu, H. Nitrogen-doped graphene with high nitrogen level via a one-step hydrothermal reaction of graphene oxide with urea for superior capacitive energy storage. RSC Adv. 2012, 2, 4498-4506. [CrossRef]

37. Lin, Z.; Waller, G.; Liu, Y.; Liu, M.; Wong, C. Facile synthesis of nitrogen-doped graphene via pyrolysis of graphene oxide and urea, and its electrocatalytic activity toward the oxygen-reduction reaction. Adv. Energy Mater. 2012, 2, 884-888. [CrossRef]

38. Lei, Z.; Lu, L.; Zhao, X.S. The electrocapacitive properties of graphene oxide reduced by urea. Energy Environ. Sci. 2012, 5, 6391-6399. [CrossRef]

39. Luhrs, C.; Phillips, J. Reductive Expansion Synthesis of Graphene. Patent 8,894,886, 25 November 2014.

40. Duarte-Moller, A.; Espinosa-Magana, F.; Martinez-Sanchez, R.; Avalos-Borja, M.; Hirata, G.A.; Cota-Araiza, L. Study of different forms of carbon by analytical electron microscopy. J. Electron Spectrosc. Relat. Phenom. 1999, 104, 61-66. [CrossRef]

41. Filippi, M.; Calliari, L. Measuring the energy of the graphite $\pi+\sigma$ plasmon peak. Surf. Interface Anal. 2006, 38, 595-598. [CrossRef]

42. Geng, D.; Yang, S.; Zhang, Y.; Yang, J.; Liu, J.; Li, R.; Sham, T.; Sun, X.; Ye, S.; Knights, S. Nitrogen doping effects on the structure of graphene. Appl. Surf. Sci. 2011, 257, 9193-9198. [CrossRef]

43. Wang, G.; Xing, W.; Zhuo, S. Nitrogen-doped graphene as low-cost counter electrode for high-efficiency dye-sensitized solar cells. Electrochim. Acta 2013, 92, 269-275. [CrossRef]

44. Li, X.; Geng, D.; Zhang, Y.; Meng, X.; Li, R.; Sun, X. Superior cycle stability of nitrogen-doped graphene nanosheets as anodes for lithium ion batteries. Electrochem. Commun. 2011, 13, 822-825. [CrossRef]

45. Reddy, A.L.M.; Srivastava, A.; Gowda, S.R.; Gullapalli, H.; Dubey, M.; Ajayan, P.M. Synthesis of nitrogen-doped graphene films for lithium battery application. ACS Nano 2010, 4, 6337-6342. [CrossRef] [PubMed]

46. Marcano, D.C.; Kosynkin, D.V.; Berlin, J.M.; Sinitskii, A.; Sun, Z.; Slesarev, A.; Alemany, L.B.; Lu, W.; Tour, J.M. Improved synthesis of graphene oxide. ACS Nano 2010, 4, 4806-4814. [CrossRef] [PubMed]

(C) 2015 by the authors; licensee MDPI, Basel, Switzerland. This article is an open access article distributed under the terms and conditions of the Creative Commons by Attribution (CC-BY) license (http://creativecommons.org/licenses/by/4.0/). 